\title{
Addition of a dairy fraction rich in milk fat globule membrane to a high- saturated fat meal reduces the postprandial insulinaemic and inflammatory response in overweight and obese adults
}

\author{
Elieke Demmer ${ }^{1}$, Marta D. Van Loan ${ }^{1,2}$, Nancy Rivera ${ }^{1}$, Tara S. Rogers ${ }^{1}$, Erik R. Gertz ${ }^{2}$, \\ J. Bruce German ${ }^{3,4}$, Jennifer T. Smilowitz ${ }^{3,4}$ and Angela M. Zivkovic ${ }^{1,3} *$ \\ ${ }^{1}$ Department of Nutrition, University of California Davis, Davis, CA, USA \\ ${ }^{2} U S D A / A R S$ Western Human Nutrition Research Center, Davis, CA, USA \\ ${ }^{3}$ Foods for Health Institute, University of California, Davis, CA, USA \\ ${ }^{4}$ Department of Food Science \& Technology, University of California, Davis, CA, USA
}

(Received 1 July 2015 - Final revision received 9 December 2015 - Accepted 15 December 2015)

Journal of Nutritional Science (2016), vol. 5, e14, page 1 of 11

doi:10.1017/jns.2015.42

Abstract

Meals high in SFA, particularly palmitate, are associated with postprandial inflammation and insulin resistance. Milk fat globule membrane (MFGM) has anti-inflammatory properties that may attenuate the negative effects of SFA-rich meals. Our objective was to examine the postprandial metabolic and inflammatory response to a high-fat meal composed of palm oil (PO) compared with PO with an added dairy fraction rich in MFGM (PO+MFGM) in overweight and obese men and women $(n$ 36) in a randomised, double-blinded, cross-over trial. Participants consumed two isoenergetic high-fat meals composed of a smoothie enriched with PO with $v$. without a cream-derived complex milk lipid fraction ( dairy fraction rich in MFGM) separated by a washout of 1-2 weeks. Serum cytokines, adhesion molecules, cortisol and markers of inflammation were measured at fasting, and at 1,3 and $6 \mathrm{~h}$ postprandially. Glucose, insulin and lipid profiles were analysed in plasma. Consumption of the PO + MFGM $v$. PO meal resulted in lower total cholesterol $(P=0.021)$, LDL-cholesterol $(P=0 \cdot 046)$, soluble intracellular adhesion molecule $(P=0.005)$ and insulin $(P=0 \cdot 005)$ incremental AUC, and increased IL$10(P=0 \cdot 013)$. Individuals with high baseline $C$-reactive protein $(C R P)$ concentrations $(\geq 3 \mathrm{mg} / \mathrm{l}, n \mathrm{~h})$ had higher $(P=0.030)$ insulin at $1 \mathrm{~h}$ after the PO meal than individuals with CRP concentrations $<3 \mathrm{mg} / \mathrm{l}(n$ 19). The addition of MFGM attenuated this difference between CRP groups. The addition of a dairy fraction rich in MFGM attenuated the negative effects of a high-SFA meal by reducing postprandial cholesterol, inflammatory markers and insulin response in overweight and obese individuals, particularly in those with elevated CRP.

Key words: Milk fat globule membrane: Postprandial inflammation: Saturated fat: Insulin: C-reactive protein: CVD: Cytokines

The postprandial state has been highlighted as an important transitory period when significant vascular damage can occur and has recently been implicated in the causal processes of $\mathrm{CVD}^{(1)}$. Postprandial inflammatory and lipaemic responses are pronounced in individuals with obesity, the metabolic syndrome (MetS) and type 2 diabetes $^{(2-5)}$, in part because the magnitude of the postprandial inflammatory response is correlated with insulin resistance ${ }^{(6,7)}$. Current literature suggests that the inflammation of the postprandial state adds to the already pro-inflammatory environment in individuals with obesity-induced metabolic disease, intensifying the overall systemic inflammation that underlies metabolic dysfunction $^{(8)}$. Given the rise in overweight and obesity worldwide ${ }^{(9)}$, potential nutritional interventions that can limit the

Abbreviations: CRP, C-reactive protein; iAUC, incremental AUC; MetS, metabolic syndrome; MFGM, milk fat globule membrane; PO, palm oil; sICAM, soluble intracellular adhesion molecule.

* Corresponding author: A. M. Zivkovic, email amzivkovic@ucdavis.edu 
postprandial inflammatory response would be of great public health benefit.

The postprandial inflammatory response is influenced by the fat content and composition of the test meal ${ }^{(10-13)}$. It has been shown that SFA induce inflammation postprandially ${ }^{(8)}$. Palmitic acid in particular appears to be detrimental. The consumption of palmitic acid acutely increases the insulin response compared with oleic acid and $n$-3 fatty acids ${ }^{(14)}$ and this was shown to be related to the adverse effects of palmitate on both $\beta$-cell function and insulin sensitivity in the postprandial state ${ }^{(15)}$. Palmitate, either as an isolated fatty acid or as part of a high-SFA meal, increases inflammatory markers in the postprandial state ${ }^{(16)}$. Palm oil (PO) is enriched in palmitate and has been used widely in the food industry as a substitute for trans-fatty acids, which are known to have deleterious effects on CVD risk ${ }^{(17)}$.

Milk fat globule membrane (MFGM) fractions have previously been reported to reduce inflammation in in vitro and animal models ${ }^{(18-21)}$. MFGM, a protein-lipid complex originating from the apical surface of mammary epithelial cells, surrounds the fat globules in milk and is found in dairy products at varying levels. Specific proteins and lipids of MFGM are associated with health-promoting bioactive functions. For example, one major MFGM-associated protein, lactadherin, was reported to bind and neutralise viruses, reduce intestinal inflammation, improve intestinal permeability, and repair intestinal epithe$\operatorname{lium}^{(20,22-24)}$. MFGM-derived polar lipids were reported to have bactericidal properties, bind enterotoxigenic pathogens and reduce intestinal inflammation ${ }^{(19,23,25-27)}$. In addition to functions attributed to its individual components, MFGM as a complex also reduced inflammation in vitro, in animals and clinically ${ }^{(18,21,28)}$. However, it is not known whether the addition of a dairy fraction rich in MFGM to meals high in saturated fat would blunt the postprandial inflammatory response in human subjects.

The objective of this study was to determine the postprandial inflammatory effect of a high-saturated fat meal using PO with and without the addition of MFGM in overweight and obese adults. We hypothesised that consuming a high-fat $\mathrm{PO}+\mathrm{MFGM}$ meal would result in lower pro-inflammatory serum markers compared with the isoenergetic PO meal.

\section{Materials and methods}

\section{Participants}

A total of seventeen adult men and nineteen adult women (total of thirty-six participants) were recruited from the Davis and greater Sacramento areas of California to participate in this study. To qualify, individuals had to be between 18 and 65 years of age, and either be overweight according to their BMI $\left(25-29.9 \mathrm{~kg} / \mathrm{m}^{2}\right)$ plus have two or more MetS traits according to the definition of the American Heart Association or simply be obese according to their BMI (30$39.9 \mathrm{~kg} / \mathrm{m}^{2}$ ) and have any number of MetS traits. The MetS is defined by having three or more of the following traits: waist circumference $>40$ inches $(>102 \mathrm{~cm})$ for men and 35 inches $(>89 \mathrm{~cm})$ inches for women; fasting plasma TAG $\geq$
$150 \mathrm{mg} / \mathrm{dl}(\geq 1.70 \mathrm{mmol} / \mathrm{l})$; fasting plasma HDL-cholesterol $<40 \mathrm{mg} / \mathrm{dl}(<1.04 \mathrm{mmol} / \mathrm{l})$ for men and $<50 \mathrm{mg} / \mathrm{dl}(<1.30$ $\mathrm{mmol} / \mathrm{l}$ ) for women; blood pressure $\geq 130 / 85 \mathrm{mmHg}$; and fasting glucose $\geq 100 \mathrm{mg} / \mathrm{dl}(\geq 5.56 \mathrm{mmol} / \mathrm{l})^{(29)}$. Individuals were excluded from participation for the following reasons: diagnosis of immune-related diseases, gastrointestinal disorders, cancer, type 2 diabetes, eating disorder, allergies to the provided study foods, poor vein accessibility according to the research phlebotomist, or a body-weight change greater than $10 \%$ over the past 6 months. Individuals were excluded from participation if they used the following: weight loss medications; daily non-steroidal anti-inflammatory drugs (NSAID); anti-inflammatory supplements; corticoid steroids; tobacco; change in hormonal birth control regimen with the past 6 months; initiation of statins in past 3 months. Because of possible confounding effects on inflammatory outcomes, dietary exclusion criteria were as follows: $>1$ serving of fish/week; $>14 \mathrm{~g}$ fibre $/ 1000 \mathrm{kcal}(4184 \mathrm{~kJ})$ per $\mathrm{d}$; $<16: 1$ of total dietary $n-6: n-3$ ratio; $>1 \%$ of daily energy as trans-fats; and a vegetarian diet pattern. If individuals had initiated an exercise programme within the past 6 months, planned to become pregnant within the next 6 months, or were already pregnant or lactating, they were not enrolled in the study. To determine enrolment eligibility, questionnaires were administered regarding health history, diet and medication. An online FFQ was used to assess dietary intake and a fasting blood sample was drawn for the analysis of blood lipids and glucose. Additional anthropometric measurements were taken during the screening visit to determine MetS traits (weight, height, and waist circumference).

This study was approved from an ethical standpoint by the Institutional Review Board of the University of California, Davis. Informed consent was given in writing by all study participants prior to starting the study protocol. The study was registered at clinicaltrials.gov under NCT01811329.

\section{Study design}

Two isoenergetic test meals were consumed by the participants in a randomised, double-blinded, two-way cross-over design. A high-fat PO meal was compared against a high-fat PO meal with the addition of MFGM (PO + MFGM). Participants were assigned to test meal order using a random number generator which randomly returned either a 0 or 1 , with a 0 being assigned to PO first followed by $\mathrm{PO}+$ MFGM second, and a 1 being assigned to PO + MFGM first followed by PO second. Test meals were consumed in random order on different test days separated by a washout phase of minimally 1 week and maximally 2 weeks to avoid any carry-over effects. After each washout, participants consumed the alternate test meal.

To limit confounding effects, the consumption of antiinflammatory supplements, alcohol or NSAID was not permitted for $72 \mathrm{~h}$ before each test day. At $24 \mathrm{~h}$ prior to the test day, vigorous exercise was prohibited to avoid increasing inflammatory markers and conversely consumption of seafood was not allowed to avoid a suppression of inflammatory markers. To ensure compliance, participants filled out a 1-d food 
record for the $24 \mathrm{~h}$ prior to each test day. The dietary records were analysed using the Nutrition Data System for Research (NDSR; University of Minnesota).

Participants arrived at the Western Human Nutrition Research Center after a 10-12 h fast on each test day. The $24 \mathrm{~h}$ diet record was collected and participants were asked to complete a modified gastrointestinal questionnaire ${ }^{(30)}$. A fasted blood sample was drawn via venepuncture. Blood pressure, heart rate, weight and waist circumference were measured. The dietary test meal was then consumed completely within $20 \mathrm{~min}$. Postprandial blood draws were conducted at 1,3 and $6 \mathrm{~h}$. These time points were determined based on previous postprandial clinical trials observing a peak in proinflammatory cytokine concentrations around 3-6 h after consuming a high-fat meal ${ }^{(6,31)}$.

Consumption of any food other than the test meal was not permitted, but bottled water was offered throughout the test day. Participants were offered the option to stay at the research facility or leave between blood draws via car to limit physical activity and had to return $15 \mathrm{~min}$ before their scheduled blood draw to allow for a 10 min rest period prior to each blood draw.

\section{Dietary challenges}

The two test meals were made up of a bagel with strawberry preserves along with either a PO or PO + MFGM smoothie. In each instance the smoothie consisted of deionised water, cream of tartar, PO shortening, and raspberry sorbet. Additionally, the PO + MFGM smoothie contained BPC50, a cream-derived complex milk lipid fraction powder $(\beta$ serum concentrate) that is a proprietary product supplied by Fonterra Co-operative Group Ltd (New Zealand) ${ }^{(32)}$. BPC50 is comprised of the following $(\% \mathrm{w} / \mathrm{w}): 52 \%$ protein of which $13.2 \%$ is membrane-derived protein, $6.6 \%$ lactose and $36.2 \%$ total fat $(22.5 \%$ TAG and $13.7 \%$ phospholipids), $0.63 \%$ gangliosides (GD3), and $5.2 \% \mathrm{ash}^{(33-35)}$. The six highest abundant MFGM-derived proteins reported in BPC50 include: fatty acid-binding protein, butyrophilin, lactadherin, adipophilin, xanthine oxidase and mucin ${ }^{(35)}$. The PO smoothie contained whey protein isolate to match the protein content found in the BPC50 product. For ingredient details, see Supplementary Table S1. Participants were instructed to eat the entire meal, rinse their cup with water, and drink the rinse-water.

Each test meal provided $40 \%$ of the participant's total daily energy intake. Energy intake was determined by using the National Academy of Sciences equation from the Institute of Medicine Dietary Reference Intake ${ }^{(36)}$. To determine each participant's physical activity level the Baecke Physical Activity questionnaire was used ${ }^{(37)}$.

The two isoenergetic test meals were constructed to vary less than $0.2 \%$ in macronutrients and provided about $55 \%$ fat, about $30 \%$ carbohydrates, and about $15 \%$ protein. Each test meal provided between 49 and $87 \mathrm{~g}$ of fat depending on each individual's energy intake, 61-107 g of carbohydrates, and $31-55 \mathrm{~g}$ of protein (Table 1). Test meal nutrient composition was estimated using NDSR (University of Minnesota).
The addition of MFGM (ranging from 53.2 to $93.1 \mathrm{~g}$ depending on each individual's energy intake) replaced $31 \%$ of the fat of each participant's meal (34\% of the total energy).

\section{Blood analyses}

Whole blood was drawn at baseline, and at 1, 3 and $6 \mathrm{~h}$ after the meal. Serum tubes were allowed to clot at room temperature for $30 \mathrm{~min}$, and then centrifuged at $1300 \mathrm{~g}$ at $4^{\circ} \mathrm{C}$ for 10 min. EDTA-whole blood tubes were kept on ice during and after blood collection and were centrifuged within $30 \mathrm{~min}$ of collection at $1300 \mathrm{~g}$ at $4^{\circ} \mathrm{C}$ for $10 \mathrm{~min}$. After centrifugation, the serum and plasma tubes were kept on ice during aliquoting. Subsequently, plasma and serum aliquots were directly frozen at $-70^{\circ} \mathrm{C}$ until analysed.

\section{Inflammatory markers}

Serum samples from all four time points were analysed for cytokine concentrations (IL-10, IL-1 $\beta$, IL-2, IL-4, IL-6, IL-8,

Table 1. Nutrient composition of test meals $†$ (Mean values and standard deviations)

\begin{tabular}{|c|c|c|c|c|}
\hline & \multicolumn{2}{|c|}{ PO meal } & \multicolumn{2}{|c|}{$\begin{array}{c}\mathrm{PO}+\mathrm{MFGM} \\
\text { meal }\end{array}$} \\
\hline & Mean & SD & Mean & SD \\
\hline Energy (kcal) & $1088 \cdot 1$ & 189.3 & $1088 \cdot 1$ & $189 \cdot 2$ \\
\hline Energy $(\mathrm{kJ})$ & 4552.4 & 791.8 & 4552.7 & 791.7 \\
\hline \multicolumn{5}{|l|}{ Total carbohydrate } \\
\hline $\mathrm{g}$ & $82 \cdot 7$ & 14.4 & 83.2 & 14.5 \\
\hline$\%$ total energy & $30 \cdot 4$ & 0.0 & $30 \cdot 6$ & 0.0 \\
\hline \multicolumn{5}{|l|}{ Total protein } \\
\hline g & $42 \cdot 5$ & 7.4 & 43 & 7.5 \\
\hline$\%$ total energy & $15 \cdot 6$ & 0.0 & $15 \cdot 8$ & 0.0 \\
\hline \multicolumn{5}{|l|}{ Total fat } \\
\hline g & $67 \cdot 3$ & $11 \cdot 7$ & 67.5 & $11 \cdot 7$ \\
\hline$\%$ total energy & $55 \cdot 6$ & 0.0 & $55 \cdot 8$ & 0.0 \\
\hline \multicolumn{5}{|l|}{ Total SFA } \\
\hline $\mathrm{g}$ & $32 \cdot 6$ & $5 \cdot 7$ & 34.6 & $6 \cdot 0$ \\
\hline$\%$ total energy & $27 \cdot 0$ & 0.0 & 28.6 & 0.0 \\
\hline \multicolumn{5}{|l|}{ Total MUFA } \\
\hline $\mathrm{g}$ & 24.6 & 4.3 & $22 \cdot 7$ & 3.9 \\
\hline$\%$ total energy & $20 \cdot 3$ & 0.0 & $18 \cdot 8$ & 0.0 \\
\hline \multicolumn{5}{|l|}{ Total PUFA* } \\
\hline $\mathrm{g}$ & $6 \cdot 9$ & $1 \cdot 2$ & $6 \cdot 1$ & $1 \cdot 1$ \\
\hline$\%$ total energy & 5.7 & 0.0 & $5 \cdot 1$ & 0.0 \\
\hline SFA 4 : 0 (butyric acid) (\%) & 0 & 0 & 0.2 & 0.0 \\
\hline SFA 6 : 0 (caproic acid) (\%) & 0 & 0 & 0.2 & 0.0 \\
\hline SFA 8 : 0 (caprylic acid) (\%) & 0 & 0 & 0.2 & 0.0 \\
\hline SFA 10 : 0 (capric acid) $(\%)^{\star}$ & 0 & 0 & 0.5 & 0.1 \\
\hline SFA 12 : 0 (lauric acid) (\%)* & 0.1 & 0.0 & 0.8 & 0.1 \\
\hline SFA 14 : 0 (myristic acid) $(\%)^{\star}$ & 0.7 & 0.1 & $2 \cdot 5$ & 0.4 \\
\hline SFA 16 : 0 (palmitic acid) $(\%)^{\star}$ & 28.7 & 5 & $24 \cdot 8$ & $4 \cdot 3$ \\
\hline SFA 18 : 0 (stearic acid) $(\%)^{*}$ & $2 \cdot 9$ & 0.5 & 4.7 & 0.8 \\
\hline MUFA $16: 1$ (palmitoleic acid) (\%)* & 0.2 & 0.0 & 0.5 & 0.1 \\
\hline MUFA $18: 1$ (oleic acid) $(\%)^{*}$ & $24 \cdot 3$ & 4.2 & $22 \cdot 2$ & 3.9 \\
\hline PUFA 18 : 2 (linoleic acid) (\%) & $6 \cdot 6$ & 1.1 & $5 \cdot 1$ & 0.9 \\
\hline PUFA 18 : 3 (linolenic acid) (\%) & 0.3 & 0.1 & 0.5 & 0.1 \\
\hline
\end{tabular}

PO, palm oil; PO + MFGM, palm oil + milk fat globule membrane * Significant difference between the two meals $(P<0.05)$.

† Comparison of the dietary challenges. Nutrient composition obtained using the Nutrition Data System for Research (NDSR). Test meals were based on each individual's total energy expenditure; thus values shown are average of all test meals ( $n$ 36). 
TNF $\alpha$, monocyte chemotactic protein-1), as well as the vascular injury molecules $\mathrm{C}$-reactive protein (CRP), serum amyloid A, soluble intracellular adhesion molecule (sICAM) and soluble vascular adhesion molecule. Plasma was used to measure IL-18 concentrations. A commercially available Multi Spot ELISA kit was used to quantify the concentrations of these markers (SECTOR Imager 2400; Meso Scale Discovery). The protocol was followed as recommended by the manufacturer. Briefly, pre-coated plates with capture antibodies were incubated with $25-50 \mu$ of serum or plasma. After washing the plates a labelled detection antibody was added. Upon electrochemical stimulation the bound detection antibodies emit light, which is measured by the plate reader to quantify the amount of each protein of interest.

\section{Cortisol}

Serum cortisol was measured at all times points using the DetectX Cortisol Enzyme Immunoassay kit (Arbor Assays). Briefly, a cortisol-peroxidase conjugate and a monoclonal cortisol antibody were added to a pre-coated ninety-six-well plate. Upon incubation, serum samples were added to each well and allowed to bind with the cortisol-peroxidase conjugate. The total amount of cortisol present in each sample was then calculated based on the absorbance detected by the reader.

\section{Metabolic parameters}

At each time point plasma glucose, insulin, and a lipid panel including TAG, total cholesterol, HDL-cholesterol, LDL-cholesterol, HDL:LDL ratio, and non-HDL-cholesterol were assessed by standard clinical techniques in the clinical laboratory of University of California Medical Center (Sacramento, CA).

\section{Clinical characteristics}

Body weight, height, waist circumference, blood pressure and heart rate were measured on each test day. Body weight was measured with a calibrated scale (6002 Wheelchair Scale; Scale-tronix). Waist circumference was measured in the standing position with measurements midway between the lateral lower rib margin and the ileac crest (QM2000 Measure Mate; QuickMedical). Height was measured with a wallmounted stadiometer (Ayrton Stadiometer Model S100; Ayrton Corporation). Blood pressure and resting heart rate were taken in the upright seated position using the appropriately sized cuff (Carescape V100 with Critikon Dura-cuf for either adults or large adults; GE Medical Instruments). Total fat mass and lean mass were assessed using dual-energy X-ray absorptiometry (Lunar Prodigy instrument; GE Medical Instruments).

\section{Statistical analysis}

The sample size was calculated based on the primary outcome marker IL-6 using the means and standard deviations from a similar human study with overweight men at risk for developing the $\mathrm{MetS}^{(31)}$. To ensure $95 \%$ confidence of the results and $80 \%$ power the sample size calculation indicated that thirty-six participants would be needed.

Statistical analyses were conducted on SPSS version 20.0 software for Macintosh (SPSS). Differences were considered significant at $P<0 \cdot 05$. Normality was established visually and numerically using histograms, Q-Q plots and the Shapiro-Wilk test. Data were transformed as needed. When concentrations for markers were below the lower limit of detection (LLOD) (IL-10; $23 \%$ and IL-6; $9 \%$ ) for $<25 \%$ of the samples, the value was calculated as the LLOD divided by 10 . When concentrations for markers were below the LLOD for $>25 \%$ of the samples, the data were excluded from statistical analyses (IL-1 $\beta$ and IL-4). Cases with values more than three box lengths from the 75 th percentile or 25th percentile were deemed outliers and removed from all analyses; this only applied to sICAM where two subjects were excluded.

To determine if dietary differences existed between test meal composition and baseline analyte concentrations a paired $t$ test was used. A mixed linear model was performed with treatment and time as fixed factors, participants as the random effect and treatment $\times$ time as the interaction term. If time was significant, multiple-comparison post hoc analysis with Bonferroni correction was carried out to compare the concentrations at 0-1 h, 0-3 h, 0-6 h, 1-3 h, 1-6 h, and 3-6 h.

The incremental AUC (iAUC, area above baseline) and decremental (area below baseline) using the conventional trapezoid method were used to compare postprandial responses between test meals ${ }^{(38)}$. The iAUC was chosen over the total AUC because it reflects the postprandial rise of these metabolite concentrations above the non-zero fasting value ${ }^{(39)}$. iAUC between test meals were compared by one-way ANOVA.

To determine if pre-existing clinical conditions affected the inflammatory responses to the test meals, secondary analyses were conducted. Participants were coded as having high or low CRP levels based on their baseline levels prior to receiving either test meal treatment. High CRP was defined as a concentration $\geq 3 \mathrm{mg} / 1$ ( $n$ 17), low CRP was defined as $<3 \mathrm{mg} / 1$ ( $n$ $19)^{(40)}$. Baseline characteristics of each CRP group can be found in Table 2. ANCOVA was used to identify statistically significant differences in postprandial inflammatory markers between test meals using CRP as the covariate variable.

\section{Results}

\section{Participant characteristics}

After screening 207 participants, thirty-eight were enrolled to start the study (Fig. 1). Thirty-six participants completed both postprandial test days. The two participants who did not finish the trial were disqualified due to scheduling difficulties and the initiation of medication that could confound the results. Each participant was randomly assigned to one test meal and after a 1- to 2-week washout period, they were crossed-over to the alternate test meal. The majority of the study population was Caucasian $(67 \%)$ or Hispanic $(28 \%)$. Out of the total thirty-six participants, six were overweight 
Table 2. Participant baseline characteristics* (Mean values and standard deviations)

\begin{tabular}{|c|c|c|c|c|c|c|c|}
\hline & \multicolumn{2}{|c|}{ All participants } & \multirow[b]{2}{*}{ MetS criteria† } & \multicolumn{2}{|c|}{ Low CRPł } & \multicolumn{2}{|c|}{ High CRPł } \\
\hline & Mean & SD & & Mean & SD & Mean & SD \\
\hline Age (years) & 42.9 & $14 \cdot 0$ & & $42 \cdot 4$ & 13.6 & $43 \cdot 6$ & 14.9 \\
\hline Weight (kg) & 92.9 & $12 \cdot 2$ & & 93.5 & 11.9 & $92 \cdot 2$ & $12 \cdot 8$ \\
\hline Height (m) & 1.7 & $0 \cdot 1$ & & $1 \cdot 7$ & 0.1 & 1.7 & 0.1 \\
\hline BMI $\left(\mathrm{kg} / \mathrm{m}^{2}\right)$ & $31 \cdot 7$ & $2 \cdot 6$ & & 31.9 & $2 \cdot 6$ & 31.5 & 2.5 \\
\hline Total body fat (\%) & $36 \cdot 7$ & 7.8 & & 34.2 & $8 \cdot 3$ & 39.5 & $6 \cdot 3$ \\
\hline Total body fat, male (\%)§ & $31 \cdot 0$ & $6 \cdot 2$ & & 28.5 & 4.3 & 35.5 & $6 \cdot 8$ \\
\hline Total body fat, female (\%)§ & 41.9 & 4.9 & & $42 \cdot 1$ & $5 \cdot 1$ & 41.7 & $5 \cdot 0$ \\
\hline Android fat $(\mathrm{g})$ & 3262.9 & 799.9 & & 40.5 & $6 \cdot 7$ & $46 \cdot 1$ & $4 \cdot 2$ \\
\hline Android fat, male (g) & $3370 \cdot 8$ & $934 \cdot 1$ & & $37 \cdot 2$ & $5 \cdot 7$ & $45 \cdot 2$ & 3.3 \\
\hline Android fat, female (g) & $3166 \cdot 3$ & 669.0 & & $45 \cdot 0$ & $5 \cdot 3$ & $46 \cdot 7$ & 4.7 \\
\hline Gynoid fat (g) & $5353 \cdot 3$ & $1452 \cdot 0$ & & 36.9 & $8 \cdot 6$ & 39.5 & $7 \cdot 0$ \\
\hline Gynoid fat, male (g) & $4829 \cdot 2$ & $1325 \cdot 8$ & & $31 \cdot 2$ & $5 \cdot 0$ & 33.5 & $5 \cdot 3$ \\
\hline Gynoid fat, female (g) & $5822 \cdot 1$ & $1430 \cdot 2$ & & 44.8 & 5.7 & $42 \cdot 7$ & 5.6 \\
\hline WC (inches) & 39.3 & $3 \cdot 2$ & & 38.8 & 2.9 & 39.9 & 3.4 \\
\hline WC, male (inches) & $41 \cdot 1$ & $3 \cdot 1$ & $>40$ & $40 \cdot 2$ & 2.9 & $42 \cdot 8$ & $2 \cdot 9$ \\
\hline WC, female (inches) & 37.7 & $2 \cdot 2$ & $>35$ & $36 \cdot 9$ & 1.6 & $38 \cdot 2$ & $2 \cdot 4$ \\
\hline WC (cm) & 99.8 & $8 \cdot 1$ & & 98.6 & 7.4 & $101 \cdot 3$ & 8.6 \\
\hline WC, male $(\mathrm{cm})$ & 104.4 & 7.9 & $>102$ & $102 \cdot 1$ & 7.4 & 108.7 & 7.4 \\
\hline WC, female $(\mathrm{cm})$ & 95.8 & $5 \cdot 6$ & $>89$ & 93.7 & $4 \cdot 1$ & $97 \cdot 0$ & $6 \cdot 1$ \\
\hline Systolic BP (mmHg) & 123.9 & $13 \cdot 6$ & $\geq 130$ & $123 \cdot 1$ & 9.5 & 124.8 & $17 \cdot 4$ \\
\hline Diastolic BP (mmHg) & $75 \cdot 0$ & $10 \cdot 3$ & $\geq 85$ & $76 \cdot 0$ & $9 \cdot 2$ & 73.9 & 11.6 \\
\hline \multicolumn{8}{|l|}{ HDL-cholesterol } \\
\hline $\mathrm{mg} / \mathrm{dl}$ & 48.3 & $14 \cdot 1$ & & 48.4 & $14 \cdot 2$ & $48 \cdot 2$ & 14.4 \\
\hline $\mathrm{mmol} / \mathrm{l}$ & 1.25 & 0.37 & & 1.25 & 0.37 & 1.25 & 0.37 \\
\hline \multicolumn{8}{|l|}{ HDL-cholesterol, male } \\
\hline $\mathrm{mg} / \mathrm{dl}$ & 43.2 & 11.7 & $<40$ & 42.5 & 13.7 & 44.5 & 7.8 \\
\hline $\mathrm{mmol} / \mathrm{l}$ & 1.12 & 0.30 & $<1.04$ & $1 \cdot 10$ & 0.35 & 1.15 & 0.20 \\
\hline \multicolumn{8}{|l|}{ HDL-cholesterol, female } \\
\hline $\mathrm{mg} / \mathrm{dl}$ & $52 \cdot 9$ & $14 \cdot 7$ & $<50$ & $56 \cdot 5$ & $10 \cdot 9$ & $50 \cdot 3$ & $16 \cdot 9$ \\
\hline $\mathrm{mmol} / \mathrm{l}$ & 1.37 & 0.38 & $<1.30$ & 1.46 & 0.28 & 1.30 & 0.44 \\
\hline \multicolumn{8}{|l|}{ Fasting glucose } \\
\hline $\mathrm{mg} / \mathrm{dl}$ & 91.0 & 7.4 & $\geq 100$ & $92 \cdot 0$ & 7.8 & 89.9 & $7 \cdot 1$ \\
\hline $\mathrm{mmol} / \mathrm{l}$ & 5.06 & 0.41 & $\geq 5.56$ & $5 \cdot 11$ & 0.43 & 4.99 & 0.39 \\
\hline \multicolumn{8}{|l|}{ Fasting TAG } \\
\hline $\mathrm{mg} / \mathrm{dl}$ & $122 \cdot 5$ & $57 \cdot 8$ & $\geq 150$ & $106 \cdot 0$ & $41 \cdot 1$ & $140 \cdot 9$ & $68 \cdot 7$ \\
\hline $\mathrm{mmol} / \mathrm{l}$ & $1 \cdot 38$ & 0.65 & $\geq 1.70$ & $1 \cdot 20$ & 0.46 & 1.59 & 0.78 \\
\hline
\end{tabular}

MetS, metabolic syndrome; CRP, C-reactive protein; WC, waist circumference; BP, blood pressure.

${ }^{*}$ Measurements taken at screening visit $(n 36)$.

† MetS as defined by the American Heart Association.

‡ Low baseline CRP $n$ 19; high baseline CRP $n 17$.

$\S$ Male $n 17$, female $n 19$.

with two MetS traits, three were overweight with three or more MetS traits, twenty-one were obese with zero to two MetS traits, and six were obese with three MetS traits. The baseline characteristics of the participants are shown in Table 2.

\section{Dietary challenge}

Participants consumed two test meals, a high-fat PO test meal and a high-fat PO + MFGM test meal. The meals (Table 1) were isoenergetic and comparable for macronutrient composition, not varying by more than $0.2 \%$ for carbohydrates, protein or fat. The total weight of SFA and MUFA did not differ between the PO $v$. PO + MFGM test meals. However, the PO meal contained a significantly higher total amount of PUFA compared with the PO + MFGM test meal. The relative abundance of $18: 2 n-6$ was not significantly different between the two test meals; however, since $18: 2 n-6$ is the predominant PUFA in the two meals, and since the PO meal had higher total PUFA, the PO meal had a higher total amount of 18 : 2n-6. The relative abundances of specific SFA and MUFA were significantly different: the PO + MFGM meal had more $10: 0,12: 0,14: 0,18: 0$ and $18: 1 n-9$ whereas the PO meal had more $16: 0$ and $16: 1 n-7$. These differences in relative abundances of fatty acids are reflective of the composition of PO, which is enriched in palmitate (16:0), and MFGM, which is enriched in medium-chain SFA characteristic of dairy fat.

\section{Metabolic parameters}

There was a time $\times$ treatment interaction for total cholesterol $(P=0 \cdot 04)$, HDL-cholesterol $(P=0 \cdot 01)$, TAG $(P<0 \cdot 0005)$, non-HDL-cholesterol $(P=0.04)$ and insulin $(P<0.0005)$ (Table 3). Among these lipid makers, the greater change in total cholesterol was observed in response to the PO test meal; there was a $5 \%$ increase from 0 to $1 \mathrm{~h}$ as well as from 0 to $6 \mathrm{~h}$. HDL-cholesterol increased from 0 to $1 \mathrm{~h}$ by $4 \%$ and decreased from 1 to $3 \mathrm{~h}$ by $4 \%$ in response to the 


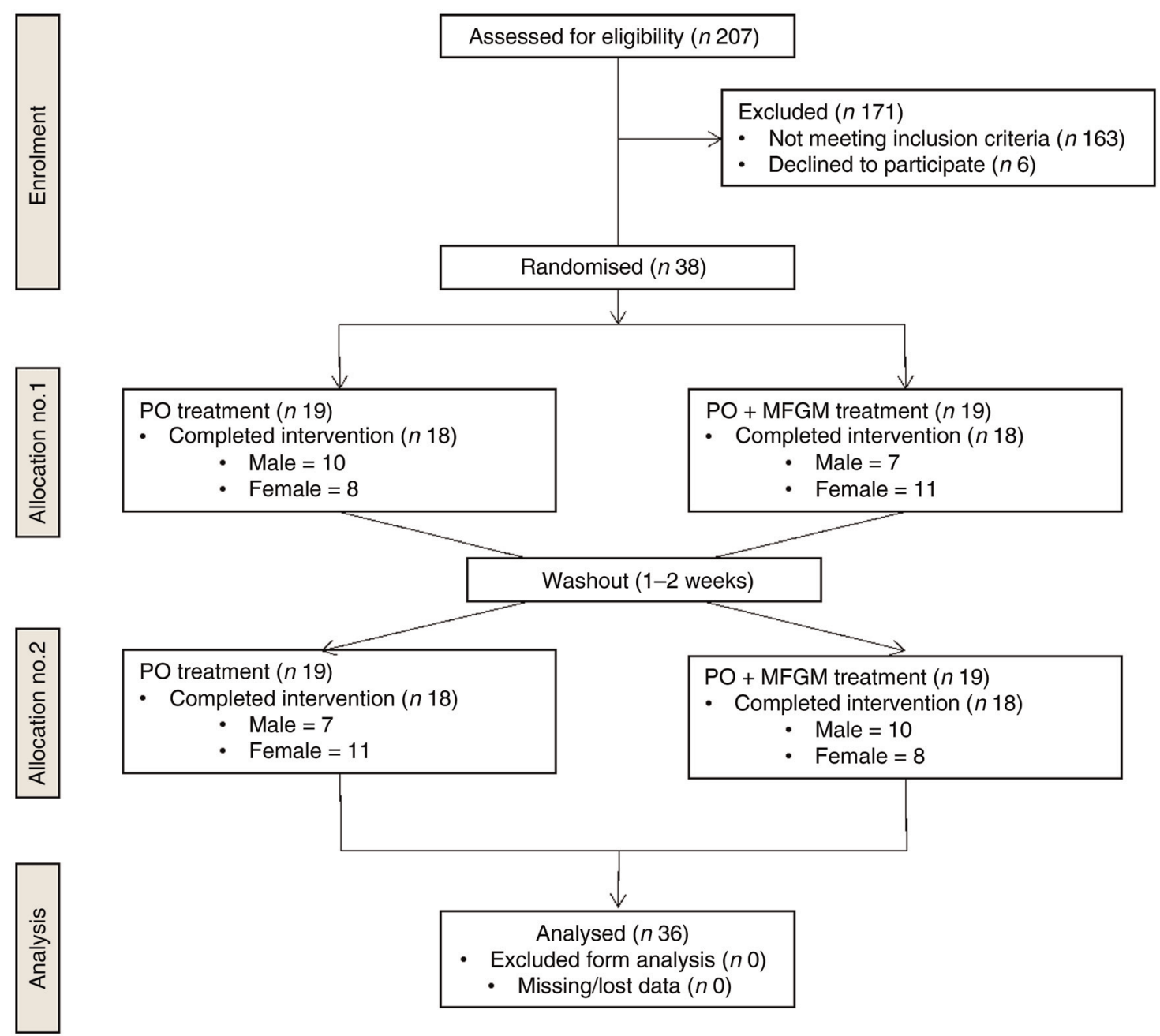

Fig. 1. Enrolment and follow-up of participants in the randomised cross-over trial. PO, palm oil; PO + MFGM, palm oil + milk fat globule membrane .

PO test meal. In response to the PO + MFGM test meal, TAG concentration increased by $104 \%$ from 0 to $3 \mathrm{~h}$ and non-HDL-cholesterol concentration increased by $22 \%$ from 0 to $1 \mathrm{~h}$.

The total concentration of each analyte over the $6 \mathrm{~h}$ postprandial time was calculated as the iAUC and compared between test meals. The addition of MFGM to the test meal resulted in significantly lower concentrations of total cholesterol $(P=0.02$ with all subjects included, $P=0.04$ with two outliers removed), LDL-cholesterol $(P=0.046)$ and a significantly higher concentration of TAG $(P=0.025)$ when compared with the PO meal alone (Supplementary Fig. S1).

When total insulin concentration was compared over the $6 \mathrm{~h}$ postprandial period (i.e. the iAUC of insulin from 0 to $6 \mathrm{~h}$ ) the addition of MFGM resulted in a significantly lower exposure to insulin ( $P=0.005)$ (Fig. 2). Neither insulin nor glucose concentrations at baseline differed between the two test meals. There were no effects of treatment on insulin and glucose concentrations in the postprandial period; however, there was a rapid increase in insulin concentration from 0 to $1 \mathrm{~h}(P<$ $0.0005)$ that was complemented by a decrease in glucose $(P$ $<0 \cdot 0005)$. From 1 to $3 \mathrm{~h}$ there was an increase back to baseline levels for glucose $(P=0.003)$ and a corresponding decrease in insulin concentrations $(P<0.0005)$ although still greater than the $0 \mathrm{~h}$ value $(P<0 \cdot 0005)$. The increase in insulin concentration was dampened from 0 to $1 \mathrm{~h}$ by more than $50 \%$ when MFGM was added to the test meal, resulting in a $482 \%$ increase $v$. a $234 \%$ increase for $\mathrm{PO} v$. $\mathrm{PO}+$ MFGM, respectively (time $\times$ treatment effect, $P<0 \cdot 0005$ ).

To examine if there was a difference between participants who had high $v$. low baseline CRP concentrations, additional secondary analyses were conducted. Participants with baseline CRP concentration $\geq 3 \mathrm{mg} / 1$ (coded as 'high') had significantly higher insulin concentrations at $1 \mathrm{~h}$ after consuming the PO meal $(P=0 \cdot 03)$. The addition of MFGM to the meal suppressed the insulin response in the high CRP group, thus removing any significant difference between the high and low CRP groups (Fig. 3).

\section{Inflammatory markers}

The two cytokines IL-1 $\beta$ and IL-4 fell below the detection limit for 70 and $95 \%$ of samples, respectively. Consequently, these markers were not included in the statistical analyses reported here. Similar results for IL-1 $\beta$ and IL-4 have been observed in previous studies ${ }^{(41,42)}$. 
Table 3. Concentrations of metabolic markers with significant interaction effects (Mean values and standard deviations)

\begin{tabular}{|c|c|c|c|c|c|c|c|c|c|}
\hline & \multicolumn{8}{|c|}{ Time point } & \multirow[b]{3}{*}{ Time $\times$ treatment: $P$} \\
\hline & \multicolumn{2}{|c|}{$\mathrm{Oh}$} & \multicolumn{2}{|c|}{$1 \mathrm{~h}$} & \multicolumn{2}{|c|}{$3 \mathrm{~h}$} & \multicolumn{2}{|l|}{$6 \mathrm{~h}$} & \\
\hline & Mean & SD & Mean & SD & Mean & SD & Mean & SD & \\
\hline Total cholesterol (mg/dl) & & & & & & & & & 0.04 \\
\hline PO meal & 194.9 & 38.5 & $204 \cdot 2^{*}$ & $40 \cdot 8$ & $201.4^{*}$ & 39.9 & $203.9^{*}$ & 39.6 & \\
\hline PO + MFGM meal & $198 \cdot 7$ & 37.6 & $199 \cdot 7$ & 37.6 & $207 \cdot 1$ & 37.4 & $203 \cdot 7$ & $35 \cdot 8$ & \\
\hline Total cholesterol (mmol/l) & & & & & & & & & 0.04 \\
\hline PO meal & 5.05 & 1.00 & $5 \cdot 29^{*}$ & 1.06 & $5 \cdot 22^{*}$ & 1.03 & $5 \cdot 28^{*}$ & 1.03 & \\
\hline $\mathrm{PO}+\mathrm{MFGM}$ meal & $5 \cdot 15$ & 0.97 & $5 \cdot 17$ & 0.97 & $5 \cdot 36$ & 0.97 & $5 \cdot 28$ & 0.93 & \\
\hline HDL-cholesterol (mg/dl) & & & & & & & & & 0.01 \\
\hline PO meal & 49.6 & 14.5 & $51 \cdot 6^{*}$ & $15 \cdot 3$ & $49.3 \dagger$ & $15 \cdot 3$ & 49.9† & $15 \cdot 3$ & \\
\hline $\mathrm{PO}+\mathrm{MFGM}$ meal & $50 \cdot 2$ & $14 \cdot 0$ & $50 \cdot 6$ & 14.5 & $50 \cdot 4$ & 14.5 & 49.7 & $14 \cdot 4$ & \\
\hline HDL-cholesterol (mmol/l) & & & & & & & & & 0.01 \\
\hline PO meal & 1.28 & 0.37 & $1 \cdot 34^{*}$ & 0.40 & $1.28 \dagger$ & 0.40 & $1 \cdot 29 \dagger$ & 0.40 & \\
\hline $\mathrm{PO}+\mathrm{MFGM}$ meal & $1 \cdot 30$ & 0.36 & 1.31 & 0.38 & 1.30 & 0.37 & 1.29 & 0.37 & \\
\hline TAG (mg/dl) & & & & & & & & & $<0.0005$ \\
\hline PO meal & $126 \cdot 6$ & 56.5 & $182 \cdot 9^{*}$ & $77 \cdot 9$ & $223 \cdot 9^{*} \dagger$ & 114.4 & $209 \cdot 6^{\star} \ddagger$ & $82 \cdot 9$ & \\
\hline PO + MFGM meal & $130 \cdot 1$ & $70 \cdot 6$ & 174.9 & $58 \cdot 2$ & $265 \cdot 1$ & $119 \cdot 8$ & $210 \cdot 4$ & $111 \cdot 8$ & \\
\hline TAG $(\mathrm{mmol} / \mathrm{l})$ & & & & & & & & & $<0.0005$ \\
\hline PO meal & 1.43 & 0.64 & $2.07^{\star}$ & 0.88 & $2.53^{*} \dagger$ & 1.29 & $2 \cdot 37^{\star} \ddagger$ & 0.94 & \\
\hline $\mathrm{PO}+\mathrm{MFGM}$ meal & 1.47 & 0.80 & 1.98 & 0.66 & 3.00 & 1.35 & $2 \cdot 38$ & 1.26 & \\
\hline Non-HDL-cholesterol (mg/dl) & & & & & & & & & 0.04 \\
\hline PO meal & $145 \cdot 4$ & $35 \cdot 3$ & $152 \cdot 6^{*}$ & 36.5 & $152 \cdot 2^{*}$ & $36 \cdot 3$ & $154 \cdot 0^{*}$ & $37 \cdot 2$ & \\
\hline PO + MFGM meal & 148.5 & 34.9 & 180.5 & $166 \cdot 6$ & $157 \cdot 0$ & 34.5 & $154 \cdot 0$ & 33.8 & \\
\hline Non-HDL-cholesterol (mmol/l) & & & & & & & & & 0.04 \\
\hline PO meal & 3.77 & 0.91 & $3.95^{*}$ & 0.95 & $3.94^{*}$ & 0.94 & 3.99* & 0.96 & \\
\hline PO + MFGM meal & 3.85 & 0.90 & 4.67 & 4.32 & 4.07 & 0.89 & 3.99 & 0.88 & \\
\hline Insulin $(\mu \mathrm{IU} / \mathrm{ml})$ & & & & & & & & & $<0.0005$ \\
\hline PO meal & $14 \cdot 0$ & $6 \cdot 1$ & $81 \cdot 7^{*}$ & $69 \cdot 3$ & $34 \cdot 4^{*} \dagger$ & $28 \cdot 6$ & Not measured & & \\
\hline $\mathrm{PO}+\mathrm{MFGM}$ meal & $16 \cdot 4$ & $10 \cdot 6$ & 54.8 & $46 \cdot 1$ & 39.6 & $25 \cdot 9$ & Not measured & & \\
\hline Insulin (pmol/l) & & & & & & & & & $<0.0005$ \\
\hline PO meal & $100 \cdot 7$ & $44 \cdot 1$ & $586 \cdot 4^{*}$ & $497 \cdot 4$ & $246 \cdot 5^{\star} \dagger$ & 205.5 & Not measured & & \\
\hline PO + MFGM meal & 117.5 & 75.9 & 392.9 & 330.4 & $283 \cdot 8$ & $186 \cdot 0$ & Not measured & & \\
\hline
\end{tabular}

PO, palm oil; PO + MFGM, palm oil + milk fat globule membrane.

* Significantly different from $0 \mathrm{~h}$ when both treatments analysed together $(P<0.05)$.

† Significantly different from $1 \mathrm{~h}$ when both treatments analysed together $(P<0.05)$.

$\ddagger$ Significantly different from $3 \mathrm{~h}$ when both treatments analysed together $(P<0.05)$.

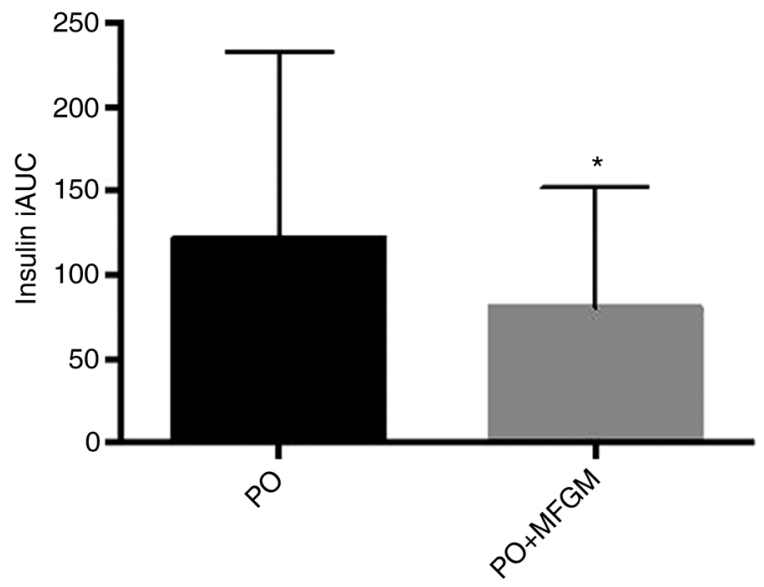

Fig. 2. Postprandial serum insulin concentrations. Serum insulin concentrations over the $6 \mathrm{~h}$ postprandial period after a high-fat mixed meal containing palm oil (PO) v. palm oil + milk fat globule membrane (PO + MFGM). Data are incremental AUC (iAUC). Values are means, with standard deviations represented by vertical bars. * The addition of MFGM resulted in a significant decrease of insulin concentration $(P=0.005)$.
Baseline concentrations of all markers related to inflammation were comparable between the two treatments. When analysed as iAUC, IL-10 was significantly higher $(P=0 \cdot 013)$ and sICAM was significantly lower in response to the $\mathrm{PO}+$ MFGM test meal ( $P=0.005$ for all) (Fig. 4). An interaction effect between time and treatment was observed for IL-10 $(P=0.03)$, IL-8 $(P=0.04)$ and sICAM $(P=0.02)$ (Table 4). Over time IL-10 gradually, but not significantly, declined on the PO treatment whereas on the PO + MFGM treatment IL-10 increased. There was a significant decrease in IL-8 from $0-3 \mathrm{~h}$ and $1-3 \mathrm{~h}$ and a significant increase in concentration from the $3-6 \mathrm{~h}$ time points $(P<0.05$ for all) following the PO meal, but IL-8 was unchanged after the PO + MFGM meal. Concentrations for sICAM significantly increased from $0-1 \mathrm{~h}, 0-6 \mathrm{~h}$, and $3-6 \mathrm{~h}$ and significantly decreased between the $1-3 \mathrm{~h}$ time points $(P<0.05$ for all $)$ after consumption of the PO meal and, like IL-8, was unchanged after the PO + MFGM challenge. There was no treatment effect observed for any of the other inflammatory markers, but a significant change over time was observed for IL-6, IL-8, TNF $\alpha$, CRP, 

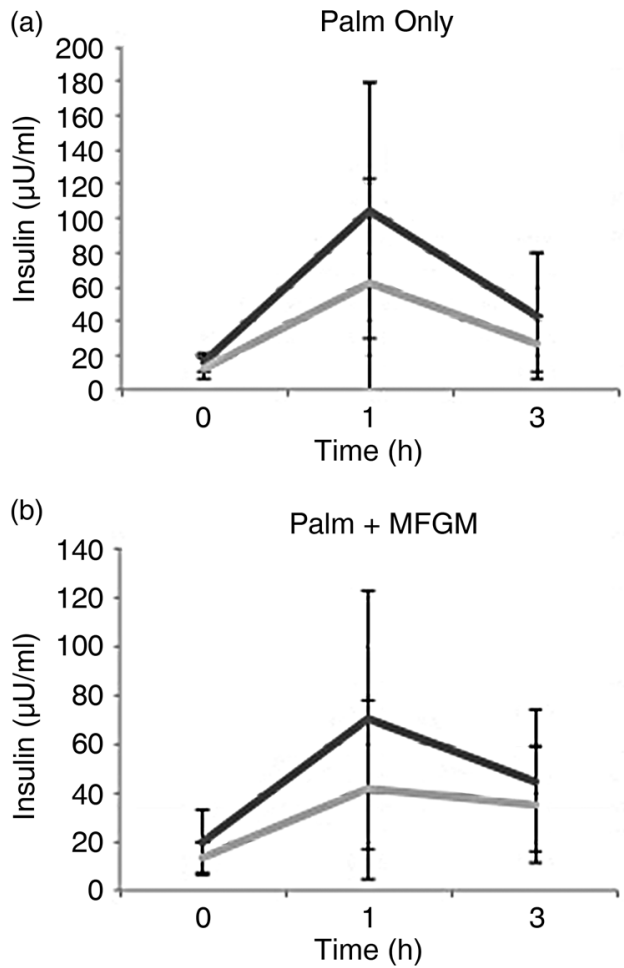

Fig. 3. Insulin concentrations in high (-) v. low (-) baseline C-reactive protein (CRP) groups. (a) There was a significant difference between the high and low baseline CRP groups at the $1 \mathrm{~h}$ time point $(P=0.03)$ after consuming the palm oil meal. (b) When the palm oil + milk fat globule membrane meal was consumed there was no difference between the high and low baseline CRP groups for insulin. Values are means, with standard deviations represented by vertical bars. To convert insulin to pmol//, multiply by 6.945 .

serum amyloid A, sICAM, soluble vascular adhesion molecule and cortisol $(P<0.05$ for all) (Table 4). There was no time or treatment effect for monocyte chemotactic protein-1.

Secondary analysis using baseline CRP as a covariate revealed a statistically significant difference for IL-6 at each time point $(P<0.05$ for each time point) between participants with high $v$. low baseline CRP concentrations after consuming the PO test meal. After consuming the PO + MFGM test meal, this difference was no longer significant, suggesting that MFGM may attenuate the postprandial inflammatory response in individuals with high CRP levels.

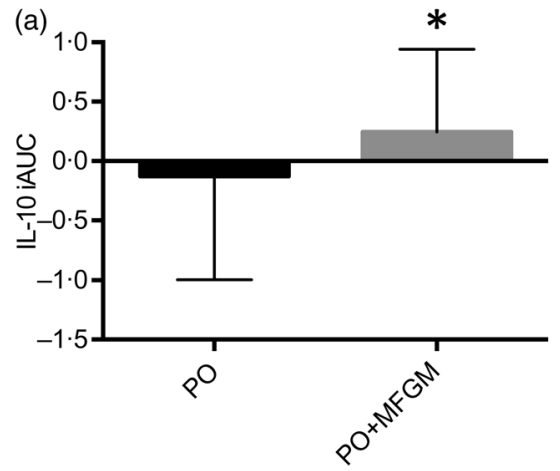

\section{Cortisol}

Analysis of serum cortisol revealed no time $\times$ treatment interaction effect or a treatment effect. There was a significant decrease in cortisol concentration for all time points $(P<$ 0.05 for all time points) over the course of each test day. Decreases throughout the day, from baseline to $1 \mathrm{~h}, 1-3 \mathrm{~h}$, and 3-6h were as follows: 15, 33 and $43 \%$, respectively. This observed decrease throughout the day is consistent with diurnal patterns of cortisol.

\section{Discussion}

This study was designed to determine if the addition of MFGM to a high-fat meal containing plant-based saturated fat influences postprandial inflammation in overweight and obese individuals. Our results showed that adding a dairy fraction rich in MFGM to a high-fat meal may lower CVD risk by reducing postprandial insulin, total cholesterol and LDL-cholesterol as well as sICAM concentrations while increasing the concentration of anti-inflammatory IL-10.

Compared with PO, consumption of the PO + MFGM test meal resulted in a significantly higher concentration of IL-10 at $6 \mathrm{~h}$ postprandial. IL-10 is an anti-inflammatory cytokine which has been recognised for its atheroprotective effects ${ }^{(43)}$. Our results suggest that the addition of MFGM to a high-SFA meal improves postprandial inflammation in an overweight and obese population already in a chronically inflamed state. To our knowledge we are the first to examine the postprandial effect on IL-10 after a high-fat dietary challenge with and without MFGM in human subjects.

Cellular adhesion molecules, such as sICAM, are key players in the early events of atherosclerosis development ${ }^{(44)}$. The consumption of the PO + MFGM test meal resulted in a significantly lower concentration of sICAM over the postprandial period when compared with PO alone. In large prospective studies of both healthy individuals and patients with CVD, concentrations of sICAM were positively associated with future incidents of $\mathrm{CVD}^{(45-47)}$. In our study the total amount of sICAM over the $6 \mathrm{~h}$ postprandial period in response to PO + MFGM was significantly lower by $95 \%$ compared with PO. These results suggest that the addition of a dairy fraction rich

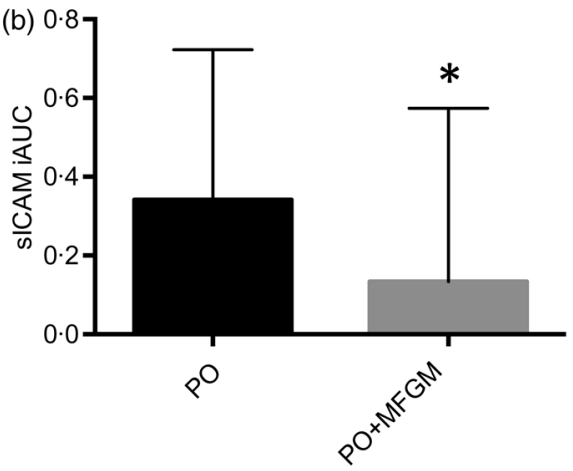

Fig. 4. Postprandial serum concentrations of IL-10 (a) and soluble intracellular adhesion molecule (sICAM) (b). Serum IL-10 and sICAM concentrations over the $6 \mathrm{~h}$ postprandial period after a high-fat mixed meal containing palm oil (PO) $v$. palm oil + milk fat globule membrane (PO + MFGM). Data are incremental AUC (iAUC). Values are means, with standard deviations represented by vertical bars. (a) ${ }^{*}$ The addition of MFGM resulted in a significant increase of anti-inflammatory IL-10 $(P=$ 0.011). (b) * The addition of MFGM resulted in a significant decrease of sICAM concentration $(P=0.013)$. The sICAM graph and data exclude two subjects who were deemed outliers with values more than three box lengths away from the 75th or 25th percentile. 
Table 4. Concentrations of measured inflammatory markers at each time point (Mean values and standard deviations)

\begin{tabular}{|c|c|c|c|c|c|c|c|c|c|}
\hline & \multicolumn{8}{|c|}{ Time point } & \multirow[b]{3}{*}{ Time $\times$ treatment: $P$} \\
\hline & \multicolumn{2}{|c|}{$\mathrm{Oh}$} & \multicolumn{2}{|c|}{$1 \mathrm{~h}$} & \multicolumn{2}{|c|}{$3 \mathrm{~h}$} & \multicolumn{2}{|c|}{$6 \mathrm{~h}$} & \\
\hline & Mean & SD & Mean & SD & Mean & SD & Mean & SD & \\
\hline \multicolumn{10}{|l|}{ IL-10 (pg/ml) } \\
\hline PO meal & 0.56 & 1.35 & 0.54 & 1.34 & 0.54 & $1 \cdot 20$ & 0.51 & $1 \cdot 30$ & 0.03 \\
\hline PO + MFGM meal & 0.49 & $1 \cdot 15$ & 0.52 & $1 \cdot 16$ & 0.52 & 1.09 & 0.57 & $1 \cdot 10$ & \\
\hline \multicolumn{10}{|l|}{ IL-6 (pg/ml) } \\
\hline PO meal & 0.74 & 1.07 & $0.59^{*}$ & 0.86 & $0.61^{*}$ & 1.08 & $0.76 \dagger \ddagger$ & $1 \cdot 14$ & 0.48 \\
\hline PO + MFGM meal & 0.72 & 1.35 & 0.59 & 1.23 & 0.54 & 0.95 & 0.76 & 1.36 & \\
\hline \multicolumn{10}{|l|}{ IL-8 (pg/ml) } \\
\hline $\mathrm{PO}$ & $11 \cdot 24$ & 3.06 & $10 \cdot 51^{*}$ & $3 \cdot 30$ & $9 \cdot 63^{*}$ & $3 \cdot 11$ & $10 \cdot 96$ & 2.91 & 0.04 \\
\hline $\mathrm{PO}+\mathrm{MFGM}$ & $11 \cdot 11$ & 3.28 & $11 \cdot 32$ & $3 \cdot 23$ & $10 \cdot 72$ & 2.66 & $10 \cdot 8$ & $3 \cdot 30$ & \\
\hline \multicolumn{10}{|l|}{$\mathrm{TNF} \alpha(\mathrm{pg} / \mathrm{ml})$} \\
\hline PO meal & 2.49 & 0.70 & 2.36 & 0.56 & $2 \cdot 29$ & 0.62 & $2 \cdot 36$ & 0.64 & 0.13 \\
\hline PO + MFGM meal & $2 \cdot 34$ & 0.66 & $2 \cdot 36$ & 0.64 & $2 \cdot 27$ & 0.61 & $2 \cdot 22$ & 0.66 & \\
\hline \multicolumn{10}{|l|}{ IL-18 (pg/ml) } \\
\hline PO meal & 145.48 & 91.64 & $148 \cdot 44$ & 75.95 & $162 \cdot 38$ & $109 \cdot 73$ & $150 \cdot 95$ & 73.05 & 0.59 \\
\hline PO + MFGM meal & $154 \cdot 25$ & $83 \cdot 16$ & $152 \cdot 19$ & 73.41 & $155 \cdot 38$ & 78.06 & $160 \cdot 03$ & 72.09 & \\
\hline \multicolumn{10}{|l|}{ MCP-1 (pg/ml) } \\
\hline PO meal & $345 \cdot 75$ & 93.66 & $343 \cdot 23$ & $104 \cdot 24$ & $336 \cdot 72$ & 94.82 & $330 \cdot 81$ & 82.09 & 0.26 \\
\hline PO + MFGM meal & $352 \cdot 16$ & 84.36 & 358.61 & $90 \cdot 41$ & $320 \cdot 46$ & $102 \cdot 57$ & 335.05 & 97.92 & \\
\hline \multicolumn{10}{|l|}{ CRP (mg/l) } \\
\hline PO meal & $4 \cdot 42$ & 4.69 & $4 \cdot 39$ & $4 \cdot 23$ & 4.42 & 4.43 & $4.64 \dagger$ & 4.64 & 0.8 \\
\hline PO + MFGM meal & $4 \cdot 37$ & 4.29 & $5 \cdot 16$ & 5.56 & $5 \cdot 11$ & 5.54 & $5 \cdot 20$ & $5 \cdot 38$ & \\
\hline \multicolumn{10}{|l|}{$\mathrm{SAA}(\mathrm{mg} / \mathrm{l})$} \\
\hline PO meal & 3.93 & 3.48 & 4.04 & 3.58 & $3.81 \dagger$ & $3 \cdot 22$ & $4 \cdot 12 \ddagger$ & $3 \cdot 71$ & 0.91 \\
\hline PO + MFGM meal & 11.85 & $30 \cdot 79$ & $12 \cdot 76$ & $32 \cdot 76$ & $12 \cdot 20$ & 31.68 & $12 \cdot 82$ & 33.37 & \\
\hline \multicolumn{10}{|l|}{ sICAM-1 (mg/l) } \\
\hline PO meal & 0.97 & 0.50 & $1.06^{*}$ & 0.53 & $1.00 \dagger$ & 0.50 & $1.04^{\star} \ddagger$ & 0.53 & 0.02 \\
\hline PO + MFGM meal & 0.96 & 0.51 & 0.97 & 0.50 & 0.95 & 0.50 & 0.97 & 0.51 & \\
\hline \multicolumn{10}{|l|}{ sVCAM-1 (mg/l) } \\
\hline PO meal & 1.55 & 0.85 & $1.65^{*}$ & 0.86 & $1.58 \dagger$ & 0.86 & $1.62 \ddagger$ & 0.86 & 0.13 \\
\hline PO + MFGM meal & 1.49 & 0.83 & 1.51 & 0.84 & 1.46 & 0.82 & 1.52 & 0.85 & \\
\hline \multicolumn{10}{|l|}{ Cortisol $(\mu \mathrm{g} / \mathrm{l})$} \\
\hline PO meal & 1139751 & 820859 & 967108 & 659595 & $703305^{*} \dagger$ & 457081 & $653937^{*} \dagger \ddagger$ & 577352 & 0.76 \\
\hline PO + MFGM meal & 1083979 & 698219 & 933085 & 619060 & 780686 & 476281 & 613297 & 366507 & \\
\hline
\end{tabular}

PO, palm oil; PO + MFGM, palm oil + milk fat globule membrane; MCP-1, monocyte chemoattractant protein-1; CRP, C-reactive protein; SAA, serum amyloid A; sICAM, soluble intracellular adhesion molecule; sVCAM, soluble vascular adhesion molecule.

* Significantly different from $0 \mathrm{~h}$ when both treatments analysed together $(P<0.05)$.

† Significantly different from $1 \mathrm{~h}$ when both treatments analysed together $(P<0.05)$.

$\ddagger$ Significantly different from $3 \mathrm{~h}$ when both treatments analysed together $(P<0.05)$.

in MFGM attenuates the atherogenic milieu triggered by the PO meal.

It is possible that the difference in sICAM between the PO $v$. PO + MFGM treatments could stem from the difference in the fatty acid composition. The PO + MFGM meal was higher in short- and medium-chained SFA and lower in $18: 2 n-6$ and $18: 1 n-9$ compared with the PO meal. Chen $e t$ al. ${ }^{(4)}$ showed that when human retinal vascular endothelial cells were treated with linoleic acid (18:2n-6) it resulted in increased ICAM expression. The MFGM preparation used is composed of complex lipids including sphingolipids, as well as bioactive proteins, which may also play roles in the observed antiinflammatory effects ${ }^{(49)}$.

When analysing the insulin iAUC over the $6 \mathrm{~h}$ postprandial period, the total insulin concentration was significantly lower in response to the PO + MFGM compared with the PO test meal. To our knowledge there have not been any prior clinical trials examining the effect of MFGM consumption on the insulin response in human subjects. One study investigated the postprandial effect of adding a dairy product rich in sphingolipids, a lipid constituent of MFGM, to a high-fat breakfast meal and found no significant difference in postprandial insulin concentrations ${ }^{(50)}$. Branched-chain amino acids may promote insulin secretion ${ }^{(51,52)}$; thus the effect of MFGM on insulin may be related to its amino acid composition.

The secondary analysis based on baseline CRP concentrations revealed that participants who were in an inflamed state (CRP $\geq 3 \mathrm{mg} / \mathrm{l}$ ) in the fasted condition had significantly higher insulin concentrations after consuming the PO meal compared with those who had normal baseline CRP concentrations. However, the addition of MFGM to the high-fat test meal completely removed this difference. These results suggest an interaction between diet and phenotype, whereby consumption of MFGM by chronically inflamed individuals normalised responses to a high-fat meal to closely resemble that of a metabolically healthy profile.

Research has shown that cortisol peaks in the morning ${ }^{(53)}$, which was reflected in the present study, and decreases over the course of the day. Elevated levels of cortisol inhibit the 
synthesis of pro-inflammatory cytokines ${ }^{(54)}$. We hypothesised that this potential inhibition may explain the observed initial decrease in the pro-inflammatory cytokines (IL-6, IL-8, TNF $\alpha$ ) from baseline (blood draw schedule between 08.00 and 09.00 hours) to the $3 \mathrm{~h}$ blood draw (scheduled between 11.00 and 12.00 hours). However, none of the correlations was significant.

In summary, the addition of a dairy fraction rich in MFGM reduced the iAUC in postprandial insulin, total cholesterol, LDL-cholesterol and sICAM responses over the $6 \mathrm{~h}$ postprandial period, and increased the production of the antiinflammatory cytokine IL-10. The addition of a dairy fraction rich in MFGM also attenuated the increases in insulin at $1 \mathrm{~h}$ in individuals with elevated fasting CRP. Results from this study suggest that the addition of a dairy fraction rich in MFGM attenuates the negative metabolic and inflammatory effects of a high-fat meal rich in saturated fat, specifically palmitate.

\section{Supplementary material}

The supplementary material for this article can be found at http://www.journals.cambridge.org/10.1017/jns.2015.42

\section{Acknowledgements}

The authors would like to thank the study participants for their time and efforts to comply with the study requirements. The authors thank Fonterra Co-operative Group Ltd (New Zealand) for supplying the BCP50 product for use in this study. The authors thank the Western Human Nutrition Research Center kitchen personnel, Dustin Burnett, Sara Dowling and Julie Edwards; phlebotomist, Jerome Crawford; physiologist, Mary Gustafson; and molecular biologist, Pieter Oort for their dedication to the project. The US Department of Agriculture is an equal opportunity employer and provider.

A. M. Z., J. T. S., J. B. G. and M. D. V. L. designed the research; E. D., N. R., T. S. R. and E. R. G. conducted the research; E. D. analysed the data; and E. D., A. M. Z., J. T. S. and M. D. V. L. wrote the paper. E. D. had primary responsibility for the final content. All authors read and approved the final manuscript.

M. D. V. L., A. M. Z. and J. T. S. have received research funding from the National Dairy Council; A. M. Z. received a stipend from the National Dairy Council to present a talk at a symposium in 2013. The founding sponsors had no role in the design of the study; in the collection, analyses, or interpretation of the data; in the writing of the manuscript, and in the decision to publish the results.

\section{References}

1. Burdge GC \& Calder PC (2005) Plasma cytokine response during the postprandial period: a potential causal process in vascular disease? BrJ Nutr 93, 3-9.

2. El Khoury D, Hwalla N, Frochot V, et al. (2010) Postprandial metabolic and hormonal responses of obese dyslipidemic subjects with metabolic syndrome to test meals, rich in carbohydrate, fat or protein. Atherosclerosis 210, 307-313.
3. Blackburn P, Després J-P, Lamarche B, et al. (2006) Postprandial variations of plasma inflammatory markers in abdominally obese men. Obesity (Silwer Spring) 14, 1747-1754.

4. Rector RS, Linden Ma, Zhang JQ, et al. (2009) Predicting postprandial lipemia in healthy adults and in at-risk individuals with components of the cardiometabolic syndrome. J Clin Hypertens (Greenwich) 11, 663-671.

5. Tushuizen ME, Pouwels PJ, Bontemps S, et al. (2010) Postprandial lipid and apolipoprotein responses following three consecutive meals associate with liver fat content in type 2 diabetes and the metabolic syndrome. Atherosclerosis 211, 308-314.

6. Nappo F, Esposito K, Cioffi M, et al. (2002) Postprandial endothelial activation in healthy subjects and in type 2 diabetic patients: role of fat and carbohydrate meals. J Am Coll Cardiol 39, 1145-1150.

7. Esposito K, Ciotola M, Sasso FC, et al. (2007) Effect of a single high-fat meal on endothelial function in patients with the metabolic syndrome: role of tumor necrosis factor- $\alpha$. Nutr Metab Cardiovasc Dis 17, 274-279.

8. Margioris AN (2009) Fatty acids and postprandial inflammation. Curr Opin Clin Nutr Metab Care 12, 129-137.

9. Ng M, Fleming T, Robinson M, et al. (2014) Global, regional, and national prevalence of overweight and obesity in children and adults during 1980-2013: a systematic analysis for the Global Burden of Disease Study 2013. Lancet 384, 766-781.

10. Deopurkar R, Ghanim H, Friedman J, et al. (2010) Differential effects of cream, glucose, and orange juice on inflammation, endotoxin, and the expression of Toll-like receptor- 4 and suppressor of cytokine signaling-3. Diabetes Care 33, 991-997.

11. Arya F, Egger S, Colquhoun D, et al. (2010) Differences in postprandial inflammatory responses to a 'modern' $v$. traditional meat meal: a preliminary study. Br J Nutr 104, 724-728.

12. Erridge C, Attina T, Spickett CM, et al. (2007) A high-fat meal induces low-grade endotoxemia: evidence of a novel mechanism of postprandial inflammation. Am J Clin Nutr 86, 1286-1292.

13. Ghanim H, Abuaysheh S, Sia CL, et al. (2009) Increase in plasma endotoxin concentrations and the expression of Toll-like receptors and suppressor of cytokine signaling-3 in mononuclear cells after a high-fat, high-carbohydrate meal: implications for insulin resistance. Diabetes Care 32, 2281-2287.

14. Shah M, Adams-Huet B, Brinkley L, et al. (2007) Lipid, glycemic, and insulin responses to meals rich in saturated, cismonounsaturated, and polyunsaturated $(n-3$ and $n-6)$ fatty acids in subjects with type 2 diabetes. Diabetes Care 30, 2993-2998.

15. Bermudez B, Ortega-Gomez A, Varela LM, et al. (2014) Clustering effects on postprandial insulin secretion and sensitivity in response to meals with different fatty acid compositions. Food Funct 5, 1374-1380.

16. Teng KT, Chang CY, Chang LF, et al. (2014) Modulation of obesity-induced inflammation by dietary fats: mechanisms and clinical evidence. Nutr J 13, 12.

17. Hayes KC \& Pronczuk A (2010) Replacing trans fat: the argument for palm oil with a cautionary note on interesterification. J Am Coll Nutr 29, 3 Suppl., 253S-284S

18. Dalbeth N, Gracey E, Pool B, et al. (2010) Identification of dairy fractions with anti-inflammatory properties in models of acute gout. Ann Rheum Dis 69, 766-769.

19. Park EJ, Suh M, Thomson B, et al. (2007) Dietary ganglioside inhibits acute inflammatory signals in intestinal mucosa and blood induced by systemic inflammation of Escherichia coli lipopolysaccharide. Shock 28, 112-117.

20. Aziz MM, Ishihara S, Mishima Y, et al. (2009) MFG-E8 attenuates intestinal inflammation in murine experimental colitis by modulating osteopontin-dependent alphavbeta3 integrin signaling. J Immunol 182, 7222-7232.

21. Snow DR, Ward RE, Olsen A, et al. (2011) Membrane-rich milk fat diet provides protection against gastrointestinal leakiness in mice treated with lipopolysaccharide. J Dairy Sci 94, 2201-2212.

22. Bu HF, Zuo XL, Wang X, et al. (2007) Milk fat globule-EGF factor 8/lactadherin plays a crucial role in maintenance and repair of murine intestinal epithelium. J Clin Invest 117, 3673-3683. 
23. Spitsberg VL (2005) Invited review: Bovine milk fat globule membrane as a potential nutraceutical. J Dairy Sci 88, 2289-2294.

24. Andersen M, Graversen H, Fedosov S, et al. (2000) Functional analyses of two cellular binding domains of bovine lactadherin. Biochemistry 39, 6200-6206.

25. El Alwani M, Wu BX, Obeid LM, et al. (2006) Bioactive sphingolipids in the modulation of the inflammatory response. Pharmacol Ther 112, 171-183.

26. Dial EJ, Zayat M, Lopez-Storey M, et al. (2008) Oral phosphatidylcholine preserves the gastrointestinal mucosal barrier during LPS-induced inflammation. Shock 30, 729-733.

27. Sanchez-Juanes F, Alonso J, Zancada L, et al. (2009) Glycosphingolipids from bovine milk and milk fat globule membranes: a comparative study. Adhesion to enterotoxigenic Escherichia coli strains. Biol Chem 390, 31-40.

28. Dalbeth N \& Palmano K (2011) Effects of dairy intake on hyperuricemia and gout. Curr Rheumatol Rep 13, 132-137.

29. Grundy SM, Cleeman JI, Daniels SR, et al. (2006) Diagnosis and management of the metabolic syndrome: an American Heart Association/National Heart, Lung, and Blood Institute scientific statement. Curr Opin Cardiol 21, 1-6.

30. Pedersen A, Sandstrom B \& Amelsvoort J (1997) The effect of ingestion of inulin on blood lipids and gastrointestinal symptoms in healthy females. Br J Nutr 78, 215-222.

31. Masson CJ \& Mensink RP (2011) Exchanging saturated fatty acids for $(n-6)$ polyunsaturated fatty acids in a mixed meal may decrease postprandial lipemia and markers of inflammation and endothelial activity in overweight men. 141, 816-821.

32. Fong B, Norris C \& McJarrow P (2011) Liquid chromatographyhigh-resolution electrostatic ion-trap mass spectrometric analysis of GD3 ganglioside in dairy products. Int Dairy J 21, 42-47.

33. MacKenzie A, Vyssotski M \& Nekrasov E (2009) Quantitative analysis of dairy phospholipids by ${ }^{31} \mathrm{P}$ NMR. J Am Oil Chem Soc 86, 757-763.

34. Guan J, MacGibbon A, Fong B, et al. (2015) Long term supplementation with $\beta$ serum concentrate (BSC), a complex of milk lipids, during post-natal brain development improves memory in rats. Nutrients 7, 4526-4541.

35. Fong B \& Norris C (2009) Quantification of milk fat globule membrane proteins using selected reaction monitoring mass spectrometry. J Agric Food Chem 57, 6021-6028.

36. National Research Council (2005) Dietary Reference Intakes for Energy, Carbobydrate, Fiber, Fat, Fatty Acids, Cholesterol, Protein, and Amino Acids (Macronutrients). Washington, DC: National Academies Press.

37. Baecke JA, Burema J \& Frijters JE (1982) A short questionnaire for the measurement of habitual physical activity in epidemiological studies. Am J Clin Nutr 36, 936-942.

38. Matthews JN, Altman DG, Campbell MJ, et al. (1990) Analysis of serial measurements in medical research. BMJ 300, 230-235.

39. Carstensen M, Thomsen C \& Hermansen K (2003) Incremental area under response curve more accurately describes the triglyceride response to an oral fat load in both healthy and type 2 diabetic subjects. Metabolism 52, 1034-1037.

40. Pearson TA (2003) Markers of inflammation and cardiovascular disease: application to clinical and public health practice: a statement for healthcare professionals from the Centers for Disease Control and Prevention and the American Heart Association. Circulation 107, 499-511.

41. Kleiner G, Marcuzzi A, Zanin V, et al. (2013) Cytokine levels in the serum of healthy subjects. Mediators Inflamm 2013, 434010.

42. Rosenberg-Hasson Y, Hansmann L, Liedtke M, et al. (2014) Effects of serum and plasma matrices on multiplex immunoassays. Immunol Res 58, 224-233.

43. Han X \& Boisvert WA (2012) The role of IL-10 in atherosclerosis. In Atherogenesis, pp. 361-384 [S Parthasarathy, editor]. http://cdn. intechopen.com/pdfs-wm/25913.pdf (accessed January 2016).

44. Blankenberg S, Barbaux S \& Tiret L (2003) Adhesion molecules and atherosclerosis. Atherosclerosis 170, 191-203.

45. Ridker PM, Hennekens CH, Roitman-Johnson B, et al. (1998) Plasma concentration of soluble intercellular adhesion molecule 1 and risks of future myocardial infarction in apparently healthy men. Lancet 351, 88-92.

46. Ridker P, Hennekens C, Buring J, et al. (2000) C-reactive protein and other markers of inflammation in the prediction of cardiovascular disease in women. New Engl J Med 342, 836-843.

47. Tanne D, Haim M, Boyko V, et al. (2002) Soluble intercellular adhesion molecule-1 and risk of future ischemic stroke: a nested casecontrol study from the Bezafibrate Infarction Prevention (BIP) Study cohort. Stroke 33, 2182-2186.

48. Chen W, Jump DB, Grant MB, et al. (2003) Dyslipidemia, but not hyperglycemia, induces inflammatory adhesion molecules in human retinal vascular endothelial cells. Invest Ophthalmol Vis Sci 44, 50165022 .

49. Contarini G \& Povolo M (2013) Phospholipids in milk fat: composition, biological and technological significance, and analytical strategies. Int J Mol Sci 14, 2808-2831.

50. Ohlsson L, Burling H, Duan R-D, et al. (2010) Effects of a sphingolipid-enriched dairy formulation on postprandial lipid concentrations. Eur J Clin Nutr 64, 1344-1349.

51. Rietman A, Schwarz J, Tomé D, et al. (2014) High dietary protein intake, reducing or eliciting insulin resistance? Eur J Clin Nutr 68 , 973-979.

52. Dugan CE \& Fernandez ML (2014) Effects of dairy on metabolic syndrome parameters: a review. Yale J Biol Med 87, 135147.

53. Van Cauter E \& Aschoff J (1989) Endocrine and other biological rhythms. In Endocrinology, 3rd ed., pp. 2658-2705 [LJ DeGroot, editor]. Philadelphia, PA: Saunders.

54. Swolin-Eide D \& Ohlsson C (1998) Effects of cortisol on the expression of interleukin- 6 and interleukin- $1 \beta$ in human osteoblastlike cells. J Endocrinol 156, 107-114. 